\title{
La educación por el arte: ¿utopía o agente de cambio social?
}

\author{
Luis Errázuriz Larraín \\ Instituto de Estética, Facultad de Filosofía, Pontificia Universidad Católica de Chile. \\ lerrazur@uc.cl
}

El presente artículo esboza algunas concepciones educativas postuladas en la revista Aisthesis, en medio de la contingencia socio-política cultural que experimenta el país desde fines de los años sesenta ${ }^{1}$.

Durante varias décadas, filósofos, artistas y educadores han promovido a través de la publicación el potencial formativo de las artes y la experiencia estética, como un aporte indispensable al desarrollo personal y social. Así, como testigos de su época y herederos de diversas escuelas de pensamiento, varias generaciones de ensayistas e investigadores han ido construyendo -por encima de sus diferencias conceptuales, políticas y estéticas- un corpus en dicho ámbito, que nos interpela a continuar imaginando y cuestionándonos frente a los desafíos que están surgiendo en nuestro tiempo.

Recorrer la trayectoria de la revista Aisthesis a lo largo de cincuenta años (19662016), no solo permite apreciar la riqueza y diversidad de contenidos abordados en sus 59 ejemplares, sino que también ofrece la posibilidad de aproximarnos, desde una perspectiva histórica, a las principales orientaciones epistemológicas y ejes curriculares que han animado la docencia, investigación y extensión del Instituto de Estética. Dicho de otro modo, la publicación constituye la principal fuente de la memoria institucional, en la cual se conservan valiosos antecedentes de los procesos de fundación, desarrollo y crecimiento que ha experimentado la unidad académica.

1 Agradezco la colaboración de Leonor Soto, quien contribuyó a revisar la publicación de la revista en el ámbito de la educación por el arte y de la educación estética, aportando valiosas referencias sobre el tema, algunas de las cuales fueron incorporadas en el presente artículo. 
La publicación fue creada en tiempos de efervescencia ideológica y cultural, al final de una década marcada por la guerra fría, la revolución cubana, el Concilio Vaticano II, el movimiento hippie y el impacto de la reforma agraria, entre otros acontecimientos político- culturales. Un período en que se agudizó la confrontación ideológica en muchas universidades del país, fenómeno que se irá crispando progresivamente hasta desembocar, el 11 de agosto de 1967, en la toma de la Casa Central de la PUC. En consecuencia, los postulados de la reforma universitaria -en especial la necesidad de reconsiderar el rol de la universidad y su inserción en la sociedad-, fueron creando una mayor conciencia, en no pocos sectores de la comunidad, en relación con los desafíos que vivía el país en aquella época.

Así, los primeros esfuerzos de la revista se concentraron en el análisis de las artes y sus problemas en Chile, línea editorial que evidencia la firme determinación de sus fundadores -(R.P.) Raimundo Kupareo y los profesores Fidel Sepúlveda y Radoslav Ivelic- de contribuir al debate y promoción de las artes a nivel nacional. En palabras del profesor Fidel Sepúlveda:

El Instituto de Estética quiere asumir su misión de Unidad Académica alerta a los signos de los tiempos, que se plantea crítica y reflexivamente frente al quehacer artístico nacional, dispuesta a investigar, registrar, difundir y estimular la capacidad creadora de nuestra comunidad; elucidar el pasado en sus aciertos y alienaciones; ubicar el arte en el lugar que le corresponde en una sociedad de cambios, sin encapsularlo en una torre de marfil ni instrumentalizarlo hipotecando su dignidad. Con ello esperamos contribuir a la definición de una política cultural que haga del arte una realidad social efectiva (7).

La revista fue inaugurada con un número dedicado al teatro y sus problemas en Chile (1966), área que históricamente ha ocupado un lugar lateral en la labor académica del Instituto de Estética. El segundo número, que incluye el aporte de prestigiados intelectuales del calibre de Sir Herbert Read y Thomas Munro, ampliará la mirada hacia la crítica de arte y sus problemas en Chile (1967), teniendo como objeto de estudio la pintura, las artes de la palabra, la música y el ballet.

En este contexto, (R.P.) Osvaldo Lira -ferviente discípulo del pensamiento tomista y una figura influyente en grupos católicos de derecha antes y durante la dictadura-, refiriéndose a la "incapacidad de captar el esplendor de la forma", plantea la necesidad de promover una "buena" educación estética en los siguientes términos:

$Y$ es sabido que, en muchos casos, no descubrimos la belleza porque no acertamos a mirarla como se debe. En otras palabras, no por defecto de cualidades innatas sino por carencia de una buena educación estética. Pero, al hablar de educación estética, no queremos referirnos solamente al contacto con obras de arte o la contemplación habitual y prolongada de la naturaleza; sino, también, y sobre todo, al enriquecimiento espiritual procurado por las disciplinas científicas e históricas, como también a los valores trascendentes de tipo ontológico y religioso (p. 94). 
A juzgar por el tenor de la cita, Lira tiene la convicción de que hay que ampliar la noción de educación estética en un sentido multidisciplinar, reivindicando su potencial formativo más allá de la mera contemplación de las artes y la naturaleza, y confiriéndole a dicha modalidad de educación un rol importante en el desarrollo de la vida espiritual y de la experiencia religiosa.

Entre los años 1968 y 1970 se publicarán los números 3, 4 y 5 de Aisthesis, dedicados a la arquitectura, la novela y la poesía, respectivamente. Sin embargo, no deja de llamar la atención que la colección monográfica haya sido interrumpida por dos ejemplares que tratan sobre la educación por el arte y sus problemas en Chile ( $\mathrm{n}^{\circ} 6$ y 7, 1971, 1972), los que fueron publicados en pleno período de la Unidad Popular². Como veremos, el concepto de "educación por el arte" tiene diversas acepciones, una de las cuales plantea que su objetivo fundamental no consiste en la formación de artistas sino en el cultivo de diversas formas de expresión (visuales, musicales y escénicas, entre otras), con el propósito de formar ciudadanos más conscientes que contribuyan a promover una sociedad libre y culturalmente robusta.

¿Qué factores pudieron haber motivado la suspensión temporal de la colección dedicada a las artes y sus problemas en Chile? ¿En qué medida la situación política imperante en aquellos años precipitó un cambio en el enfoque editorial, desde la filosofía y la teoría de las artes hacia la educación por el arte?

No cabe duda de que el gobierno de la Unidad Popular y el ambiente de radicalización vivido en Chile durante aquel período demandaron un rol más protagónico de los artistas y las universidades como agentes de cambio y transformación social. Sin embargo, indistintamente del grado de influencia que pudo haber tenido la contingencia política en el giro que experimentó la colección temática, el hecho de que se haya decidido ampliar el horizonte de la revista hacia el campo de la educación por el arte evidencia la voluntad de contribuir al desarrollo cultural del país; y, más específicamente, a la reforma educacional que se estaba impulsando en aquella época. En otras palabras, además de promover la reflexión teórica sobre las bellas artes y la estética, la publicación debía cumplir un rol más protagónico en la difusión de ideas y propuestas, reivindicando el potencial educativo de las artes como una medio para impulsar el desarrollo cultural y social del país. El profesor Gaspar Galaz expresa este propósito en los siguientes términos:

La educación y el arte son los medios por los cuales miles y miles de hombres pueden integrarse a los cambios, donde pretendemos que al arte le competa un papel importante como elemento formador. Tenemos que romper con lo que conocemos como "público culto" y hacer de nuestra sociedad un todo di-

2 Para una aproximación al gobierno de la Unidad Popular y a la función que desempeñaron no pocos artistas, véase Errázuriz, Leiva 2012: "Aunque la evaluación de lo ocurrido durante este período puede variar de acuerdo a diversas perspectivas históricas, políticas y culturales, hay consenso en que se trató de una época de aguda agitación social. Fueron años de confrontaciones y polarización, de ilusiones y traumas, años en que maduraron conflictos y anhelos frustrados que se arrastraban hacía mucho tiempo y que terminaron colapsando el sistema democrático." 
námico en que cada persona reciba lo necesario para actualizar cada vez más sus potencialidades, sin fronteras, sin diferencias de tipo cultural y económico, que son los primeros ladrillos en la larga muralla que origina las diferencias sociales que separan a los hombres (38).

En consecuencia, con un sentido de responsabilidad social frente a las carencias y desafíos culturales del país, la revista Aisthesis intentará promover el valor formativo de las artes y de la experiencia estética más allá de las élites y los públicos ilustrados. Así, el lema de la educación por el arte se transformará en una plataforma capaz de aglutinar a los docentes e inspirar la misión del Instituto de Estética en torno a un proyecto compartido, el que será interpretado transversalmente desde diversas perspectivas, entre las cuales destacamos, a modo de ejemplo, las siguientes propuestas: "necesidad de educar a la comunidad" (Ivelic 58); transformar el Museo Nacional de Bellas en "la gran sala de clases a nivel nacional" (Antúnez 168); y fomentar la creación como artista o la recreación como espectador activo (Ivelic 93).

Resulta interesante constatar que la idea de educar por el arte, postulada en 1906 por el destacado pintor nacional Juan Francisco González (Errázuriz 102), encuentra recién a finales de la década de los sesenta un contexto histórico más propicio para su divulgación en América Latina. En efecto, el clima imperante en Chile en aquella época, caracterizado por un creciente anhelo de renovación y cambio y, en no pocos casos, por un ímpetu revolucionario que busca la refundación del país, además de la presencia de una generación de maestros influenciada por el ambiente reformista que se vive en las universidades, en la Iglesia Católica (Vaticano II) y en otros ámbitos, son factores que ciertamente contribuyen a generar una atmósfera más receptiva hacia los postulados de la educación por el arte como una forma de compromiso con la realidad.

Paradójicamente, dicha concepción educativa se remonta a una de las tesis de Platón: el arte debe ser la base de toda forma de educación (Ruiz 80), abarcando el cultivo de múltiples formas de expresión (visuales, verbales, auditivas, entre otras):

[...] la belleza, la armonía, la gracia y el número del discurso son expresión de la bondad del alma [...] ¿ No deben aplicarse nuestros jóvenes guerreros a adquirir todas esas cualidades si quieren cumplir a conciencia con sus deberes? -Indudablemente. Tal es, a lo menos, el objeto de todas las artes, de la pintura, de la escultura, del bordado, de la arquitectura y de la propia naturaleza en la producción de las plantas y de los cuerpos. Necesitamos [...] buscar artistas hábiles, capaces de seguir las huellas de la naturaleza de lo bello y de lo gracioso, para que nuestros jóvenes, criados entre sus obras como en un ambiente puro y sano, reciban sin cesar de ellas saludables impresiones por ojos y oídos, y que desde la infancia todo les mueva insensiblemente a imitar, a amar lo hermoso, y a establecer entre ello y ellos mismos un perfecto acorde. No habría nada mejor que semejante educación (80). 
En otras palabras, tuvieron que transcurrir dos mil cuatrocientos años, aproximadamente, para que la teoría de Platón fuera reciclada por el filósofo y crítico de arte inglés, Sir Herbert Read, quien, gracias a su vocación humanista y profunda convicción respecto a la necesidad de formar integralmente a los ciudadanos, publica, en plena Segunda Guerra Mundial, Education through Art (1943). El libro, fruto de una investigación realizada en la Universidad de Londres (1940-1942), se transformó en un clásico a nivel internacional, con innumerables ediciones en muchos idiomas $y$, al final de los años cincuenta, fue traducido al español, propagándose como un manifiesto en América Latina (Errázuriz). Años más tarde, Read reformulará su teoría como una "política revolucionaria", cuyo principal objetivo es establecer una educación en arte que desarrolle los poderes imaginativos y creativos de los niños: para el mundo externo puede parecer inofensiva, pero aquellos que han seguido las implicancias de este objetivo saben que está envasado con suficiente dinamita para hacer volar el actual sistema educativo y generar una revolución en toda la estructura de nuestra sociedad (Read 1).

La utopía de cambiar radicalmente el sistema educativo -y en última instancia, la sociedad-mediante la educación por el arte, con el fin de despertar las capacidades imaginativas y creativas de la niñez y la juventud, no prosperó en la Inglaterra de Read.

Por su parte, el movimiento precursor de la educación por el arte impulsado por la revista Aisthesis tampoco llegaría muy lejos. El golpe de Estado del 11 de septiembre de 1973 y, consecuentemente, el colapso del sistema democrático, cambió abruptamente el rumbo en muchos ámbitos de la vida nacional, impactando no pocas instituciones universitarias y, por consiguiente, también sus programaciones y líneas editoriales. La revista Aisthesis no fue una excepción: como un sismógrafo cultural, acusó el impacto de las réplicas que afectaron a los medios de comunicación. Prueba de ello es que, a lo largo de cinco décadas (1966-2016), el único año en que se dejó de imprimir fue el de la "intervención militar". En consecuencia, el número dedicado a la música y sus problemas en Chile tuvo que publicarse un año más tarde (1974). ¿En qué medida fue necesario suprimir algunos artículos y/o reeditar sus contenidos para capear la censura impuesta por el régimen?

Cualquiera haya sido la causa del silencio de la revista Aisthesis el año del golpe, lo cierto es que su línea editorial tuvo que adaptarse al nuevo escenario dictatorial, tanto es así que los números 6 y 7, dedicados a la educación por el arte y sus problemas en Chile, permanecieron almacenados en una bodega para prevenir su difusión. Y no es de extrañar. Dado el clima de control y censura que se vivía en Chile, bastaba con una afirmación como "El arte desafía toda clase de dictaduras" (Kupareo 18), para que existieran verdaderas aprehensiones que debían tomarse en serio y con la debida cautela.

Así, la difusión de ideas en torno a la educación por el arte será cada vez más esporádica en la revista Aisthesis y, con el transcurrir de los años, irá desapareciendo progresivamente para dar paso a diversas concepciones en torno a la educación estética y a la educación artística. 
En síntesis, la pretensión utópica de Read de que sería posible refundar el sistema educativo a través de las artes -que en aquella época despertó el interés de no pocos de nosotros- no solo subestimó las complejidades del sistema escolar y las resistencias propias de un modelo de sociedad dominado por un paradigma técnico instrumental, sino también ignoró que las decisiones ligadas a la construcción del currículo suelen darse en un campo de batalla donde hay muchos intereses en juego. Si a este escenario sumamos una relación inversamente proporcional entre la pulsión por hacer cambios y la carencia de estrategias coherentes para alcanzar dichos cambios, el resultado obtenido no supera la mera ilusión de un sueño idealista. En definitiva, el intento de convertir el arte en un medio para despertar las consciencias y los poderes creativos -transformándolo en una suerte de religión (Barzun)-, junto con concebir la educación como un templo desde el cual podríamos cambiar el mundo, no prosperó.

Como reflexión final, cabe preguntarse: ¿en qué medida el sentido de responsabilidad social que animó a los fundadores de la revista Aisthesis tiene validez en nuestro tiempo?

Más allá de los aciertos, sueños y fracasos que podemos reconocer a lo largo del tiempo, e indistintamente de las prioridades y/o énfasis editoriales de cada época, la necesidad de difundir el potencial formativo de las artes y de la experiencia estética debería continuar siendo un objetivo fundamental de la revista Aisthesis.

Por otra parte, si queremos fomentar el valor de la educación estética en relación con diversos ámbitos de la producción simbólica, y más allá del sistema escolar, no solo sería necesario reivindicar su valor intrínseco en una cultura dominada por intereses pragmáticos y mercantiles, tendríamos también que aportar a la formación de ciudadanos más sensibles frente a los múltiples desafíos de nuestros tiempo. Nos referimos especialmente a los que surgen de la crisis medioambiental ${ }^{3}$, de la creciente realidad multicultural y del impacto de las tecnologías emergentes, entre otros.

En síntesis, si fuéramos capaces de contribuir al desarrollo de una mayor sensibilidad estética y, por ende, de una conciencia más lúcida y crítica en relación con el mundo que estamos viviendo, y si pudiéramos estimular la capacidad de concentrar la atención de un modo imaginativo y reflexivo en las sensaciones que percibimos (Klaus), estaríamos contribuyendo a mejorar la calidad cultural de la educación de las futuras generaciones.

3 Véanse: Laudato Sí, Carta Encíclica de S.S. Francisco sobre el cuidado de la casa común (2015). Conferencia de las Naciones Unidas sobre Cambio Climático 2015. Acuerdo de París firmado por 195 países. 


\section{Referencias}

Barzun, Jacques, “The Rise of Art as Religion”. The Use and Abuse of Art. Washington, DC: The National Gallery of Art, Princeton University Press, 1974. Impreso.

Errázuriz, Luis Hernán. Historia de un Área Marginal. La Enseñanza Artística en Chile, 1797-1993. Santiago: Ediciones Universidad Católica de Chile, 1993. Impreso. ---. Sensibilidad Estética: Un Desafío Pendiente en la Educación Chilena. Santiago: Instituto de Estética Pontificia Universidad Católica de Chile / Frasis Editores, 2006. Impreso.

Errázuriz, Luis Hernán y Leiva, Gonzalo. “El Golpe Estético”. Dictadura Militar en Chile 1973-1989. Santiago: Ocho Libros, 2012. Impreso.

Mollenhauer, Klaus. “¿Es posible una formación estética?” Educación 42 (1990). Impreso.

Read, Herbert, Education through Art: a Revolutionary Policy. Londres: London University College, 1965. Impreso.

Ruiz, Carlos. "Educación por el Arte, de H. Read”. Conferencia en la Cátedra UnEsco. Revista Aleph (2000). Impreso. 